This item was submitted to Loughborough's Research Repository by the author.

Items in Figshare are protected by copyright, with all rights reserved, unless otherwise indicated.

\title{
Acoustic emission signal processing framework to identify fracture in aluminum alloys
}

PLEASE CITE THE PUBLISHED VERSION

https://doi.org/10.1016/j.engfracmech.2018.04.027

\section{PUBLISHER}

(c) Elsevier

\section{VERSION}

AM (Accepted Manuscript)

\section{PUBLISHER STATEMENT}

This work is made available according to the conditions of the Creative Commons Attribution-NonCommercialNoDerivatives 4.0 International (CC BY-NC-ND 4.0) licence. Full details of this licence are available at: https://creativecommons.org/licenses/by-nc-nd/4.0/

\section{LICENCE}

CC BY-NC-ND 4.0

\section{REPOSITORY RECORD}

Wisner, Brian, K. Mazur, V. Perumal, Konstantinos Baxevanakis, L. An, G. Feng, and A. Kontsos. 2019. "Acoustic Emission Signal Processing Framework to Identify Fracture in Aluminum Alloys". figshare. https://hdl.handle.net/2134/33840. 


\title{
Acoustic Emission Signal Processing Framework to Identify Fracture in Aluminum Alloys
}

\author{
B. Wisner ${ }^{1}$, K. Mazur ${ }^{1}$, V. Perumal ${ }^{1}$, K.P. Baxevanakis², L. An ${ }^{3}$, G. Feng ${ }^{3}$, \\ and A. Kontsos ${ }^{1, *}$ \\ ${ }^{1}$ Theoretical and Applied Mechanics Group, Department of Mechanical Engineering 83 Mechanics, Drexel \\ University, USA \\ ${ }^{2}$ Wolfson School of Mechanical, Electrical and Manufacturing Engineering, \\ Loughborough University, LE11 3TU, UK \\ ${ }^{3}$ Department of Mechanical Engineering, Villanova University, USA \\ *Corresponding Author: antonios.kontsos@drexel.edu, Tel: +1 215-895-2297
}

\begin{abstract}
Acoustic emission (AE) is a common nondestructive evaluation tool that has been used to monitor fracture in materials and structures. The direct connection between AE events and their source, however, is difficult because of material, geometry and sensor contributions to the recorded signals. Moreover, the recorded AE activity is affected by several noise sources which further complicate the identification process. This article uses a combination of in situ experiments inside the scanning electron microscope to observe fracture in an aluminum alloy at the time and scale it occurs and a novel AE signal processing framework to identify characteristics that correlate with fracture events. Specifically, a signal processing method is designed to cluster AE activity based on the selection of a subset of features objectively identified by examining their correlation and variance. The identified clusters are then compared to both mechanical and in situ observed microstructural damage. Results from a set of nanoindentation tests as well as a carefully designed computational model are also presented to validate the conclusions drawn from signal processing.
\end{abstract}

Keywords: Acoustic emission, fracture, microscopy, mechanical behavior, aluminum alloys 


\section{Introduction}

The Acoustic Emission (AE) method, formally defined (per ASTM E1316) as the release of transient elastic waves from irreversible processes, has been used in several applications to detect fracture at both laboratory $[1-8]$ and field conditions $[9,10]$ for a broad range of materials including metallic $[1$, $2,5,6,11-20]$, composites [3, 21-28], and concrete $[9,10,29,30]$, among others. The data postprocessing of AE-related sensing has been exhaustively explored since in contrast with other acoustics nondestructive testing and evaluation (NDT\&E) methods, AE lacks the precise information related to the source (e.g. compared to ultrasonics testing) which complicates efforts to relate $\mathrm{AE}$ activity to e.g. fracture location and size.

Standard AE data processing utilizes features extracted from the recorded waveforms of the typical $\mathrm{AE}$ activity. Coupling between AE features and fracture is most commonly performed by using a specific loading scheme, material and specimen designed to only promote certain damage mechanisms, then recording in situ $\mathrm{AE}$ activity and verifying in post mortem the presence of the $a$ priori expected damage using, also typically, microscopy and fractography tools. For example, Roberts et al. linked AE count rate with crack growth $[19,31]$ in an effort to predict the materials remaining life, while others also attempted to identify noise sources such as friction [32]. Similar methods have been used to link observed $\mathrm{AE}$ data-trends with fracture $[2,4,13,15,18,20,33]$ and crack growth $[1,16,19,31,34-38]$ in metallic materials. In the case of composite materials, features such as the frequency content of the AE signals have been suggested for identifying damage mechanisms $[22,39]$. Specifically, the highest frequency signals have been suggested to be linked to 
fiber breakage [39], while the lower (intermediate) frequency ones are often linked to mechanisms such as matrix fracture or fiber pull outs [26].

In addition to features, the burst or continuous nature of recorded AE waveforms coupled with the activation region in the stress-strain curve $[5,7,13,17,25,39,40]$ has also been used to identify $\mathrm{AE}$ signals related to damage [41]. In the case of metals, frequency and burst or continuous nature of $\mathrm{AE}$ waveforms have been reported as a way to identify particular mechanisms such as particle fracture in precipitate hardened aluminum alloys [14, 15, 18, 35, 42, 43].

Furthermore AE data has been coupled and cross-validated with a variety of other NDE techniques including infrared thermography [20,44], digital image correlation [5, 7-9, 12, 20, 25, 40, 45, 46] , ultrasonic testing [30, 47], and visual inspection either through imaging [9, 20, 48, 49], or microscopy $[1,50-55]$. Specifically, in relation to fracture events, AE monitoring has been coupled with DIC to identify the onset of visible crack growth to identify AE signals that can be attributed to this damage mechanism. Similar procedures have been implemented to investigate larger fracture events including visible crack initiation and growth by coupling AE with DIC to identify reliably the presence of a crack and link it to specific $\mathrm{AE}$ features $[4,7,20]$. In situ monitoring of microstructural changes during loading has substantiated the claims from ex situ experiments as to the initiation and evolution of specific damage mechanisms at key points in the loading curve allowing for validation of the source of AE signals. The authors of the present article have extended this concept of in situ monitoring inside the Scanning Electron Microscope (SEM) coupled with AE and DIC to identify particle fracture in precipitate hardened alloys in almost real time directly at the scale it 
occur $[5,33]$. In this way, it was possible to link the in situ damage observed at the time and scale it occurs to AE activity.

Furthermore, machine learning tools have been also used to correlate AE content with fracture and damage in general. Specifically, both unsupervised [39, 56-58] and supervised [30] clustering algorithms are commonly used to separate noise from damage sources using features that are selected to achieve the desired clustering. Among these methods, k-means clustering is the most commonly used to separate AE signals based on feature characteristics. This method has been used to separate damage signals such as cracks from other AE signals [59,60], as well as examine the different damage states of a material based on the evolution of the clusters [57]. Some authors even used the k-means approach to allow the quantification of uncertainty in the clustering [39, 61]. Other researchers have coupled data reduction techniques such as Principle Component Analysis (PCA) with k-means to produce reliable separation of the AE data with only the first two principle components [60]. Supervised pattern techniques including support vector machines [21, 30, 62, 63], Neural Networks [21, 27, 64], and Hidden Markov Chains [41, 64] have been used to isolate specific sources of AE signals as well as to successfully denoise the AE data. Moreover, knowledge of the damage processes and the points they initiate during loading can be used to connect clusters to potential sources. This process has been used to identify AE clusters that are most probable to represent composite damage mechanisms such as matrix cracking and fiber breakage [27, 64, 65]. Similar efforts have been made in metals where knowledge of the ductile nature of precipitate-hardened $\mathrm{Al}$ alloys vs the brittle nature of the inclusions provided a way to separate particle fracture clusters from noise and possible 
dislocation signals $[2,5,18,35]$. Such methods have been also implemented to separate twinning and dislocation behaviors in $\mathrm{Mg}$ alloys specimens $[17,58]$.

In this context, this article presents a novel framework to post process AE data related to fracture in a commercially available aluminum alloy. To establish this framework the quality of the used datasets was of primary concern and therefore all experimental datasets are obtained by a one-of-akind setup developed previously by the authors $[5,6]$ that includes testing inside the SEM chamber while simultaneously recording $\mathrm{AE}$ at a scale that both incubation and initiation of fracture can be monitored directly. Leveraging such datasets, a workflow for AE data post processing is developed that targets both a more objectified selection of the features that are then used in clustering, as well as on the use of temporal and spatial microstructural characteristics to further select feature combinations in clustering related to fracture. It is argued therefore that such post-processing workflow would be impossible to validate without the experimental and computational part of this investigation which, however, can be extended to other cases of fracture across materials and scales.

\section{Experimental Procedure}

\subsection{Material and Specimen Geometry}

A precipitate hardened aluminum alloy, Al2024-T3, was used for this work in the as-received condition. The material contains up to $5 \% \mathrm{Cu}, 1.8 \% \mathrm{Mg}, 1 \% \mathrm{Mn}, 0.5 \% \mathrm{Fe}, 0.5 \% \mathrm{Si}$ and trace amounts of $\mathrm{Cr}$ and $\mathrm{Zn}$. The $\mathrm{Al}$ sheet was rolled to $2.5 \mathrm{~mm}$ nominal thickness and a small piece was cut from the plate and mechanically polished to $0.05 \mu \mathrm{m}$ alumina suspension to identify the grain structure and texture. The average grain size is $50 \mu \mathrm{m}$ with a strong rolling texture. Therefore, 
specimens were cut with the rolling and loading directions aligned to reduce texture effects on damage incubation. The specimen geometry is shown in Figure 1a where the hourglass shape in the gage section (which is identified by the highlighted rectangle in the middle of the specimen) is used in conjunction with a nanoindented grid pattern $[6,46]$ to allow more focused observations during in situ monitoring inside the SEM. Furthermore, the larger section on either end of the specimen is used to attach AE sensors in the locations indicated by the circles in Figure 1a.

\subsection{Mechanical and Nondestructive Testing Setup}

Loading was achieved using a microscale testing device (made by GATAN) equipped with a 2100N load cell inside a FEI XL30 ESEM. The load was applied monotonically at a rate of $0.1 \mathrm{~mm} / \mathrm{min}$ until catastrophic failure ensuring the data collected represents all stages of the failure process.

\section{(a)}

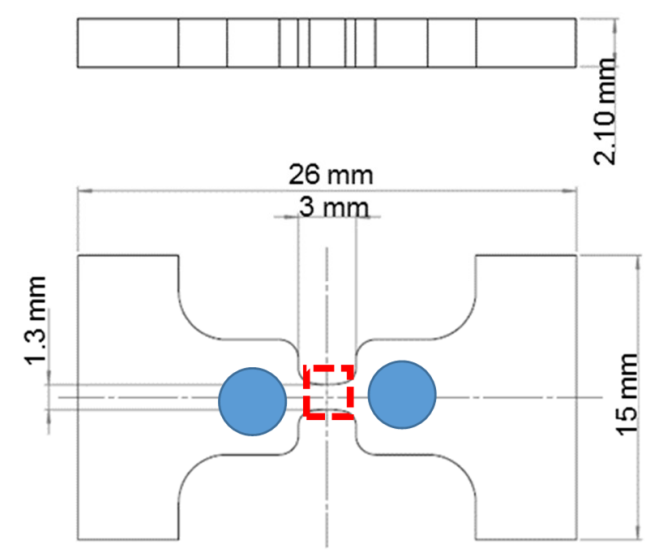

(b)

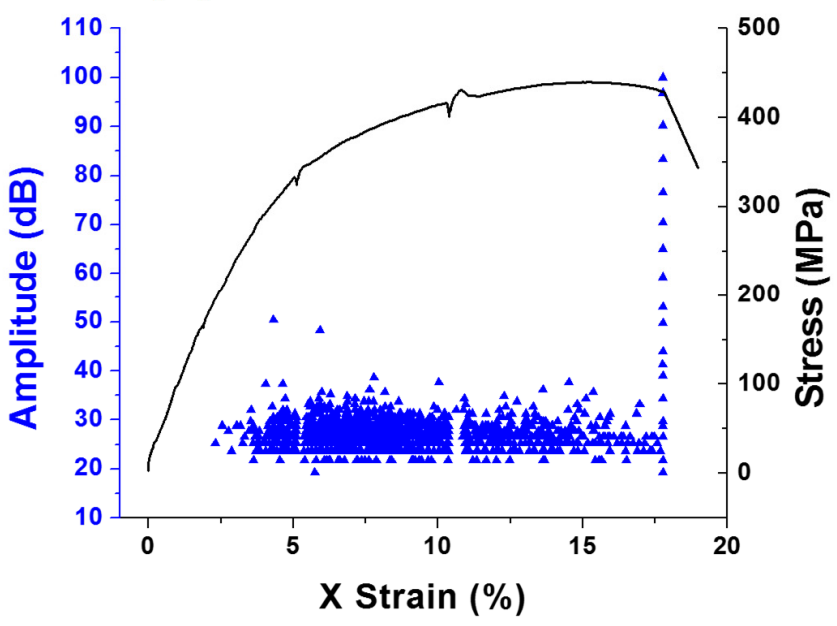

Figure 1: (a) Specimen geometry with sensor locations marked as blue circles, (b) Load curve with AE activity overlaid as amplitude.

Cyclic loading to a maximum of $800 \mathrm{~N}$ with an $\mathrm{R}$ ratio of 0 , indicating a minimum load of $0 \mathrm{~N}$, was also applied to observe the damage initiation process and resulting AE data. As the loading was 
conducted in the SEM with in situ monitoring using the same screw driven device as was used for the monotonic case, the load was applied at the same rate of $0.1 \mathrm{~mm} / \mathrm{min}$ with approximately a one minute dwell at the peaks to obtain higher resolution images. In addition, nanoindentations were performed on specifically targeted areas of some of the specimens tested using a MTS Agilent G200 nanoindenter with a cube corner tip. To relate the AE signals with the observed damage, each specimen was monitored during loading using secondary electron (SE) imaging by recording low resolution (720 X 480 pixels) video during the entire test and high resolution (1296 x 962 pixels) images obtained every $200 \mathrm{~N}$ until failure in the monotonic loading condition and at every peak and valley for the cyclic condition. A test matrix listing the available AE data used for validation of the machine learning results by using in situ observed damage mechanisms and simultaneously recorded $\mathrm{AE}$ waveforms is given in Table 1.

Table 1: Test Matrix of Available AE Data with in situ SEM observations

\begin{tabular}{|c|c|c|c|}
\hline Specimen & $\begin{array}{c}\text { Loading } \\
\text { Scheme }\end{array}$ & $\begin{array}{c}\text { Catastrophic } \\
\text { Failure }\end{array}$ & $\begin{array}{c}\text { Number of } \\
\text { Tests }\end{array}$ \\
\hline \multirow{2}{*}{$\begin{array}{c}\text { Double Sharp } \\
\text { Notch }\end{array}$} & Monotonic & No & 7 \\
\cline { 2 - 4 } & Monotonic & Yes & 6 \\
\cline { 2 - 4 } & Cyclic & No & 2 \\
\hline \multirow{2}{*}{ Dogbone } & Monotonic & No & 1 \\
\hline \multirow{2}{*}{ Notched - } & Cyclic & Yes & 1 \\
\hline Bending & Monotonic & No & 1 \\
& Monotonic & Yes & 1 \\
\hline & Cyclic & No & 1 \\
\hline
\end{tabular}



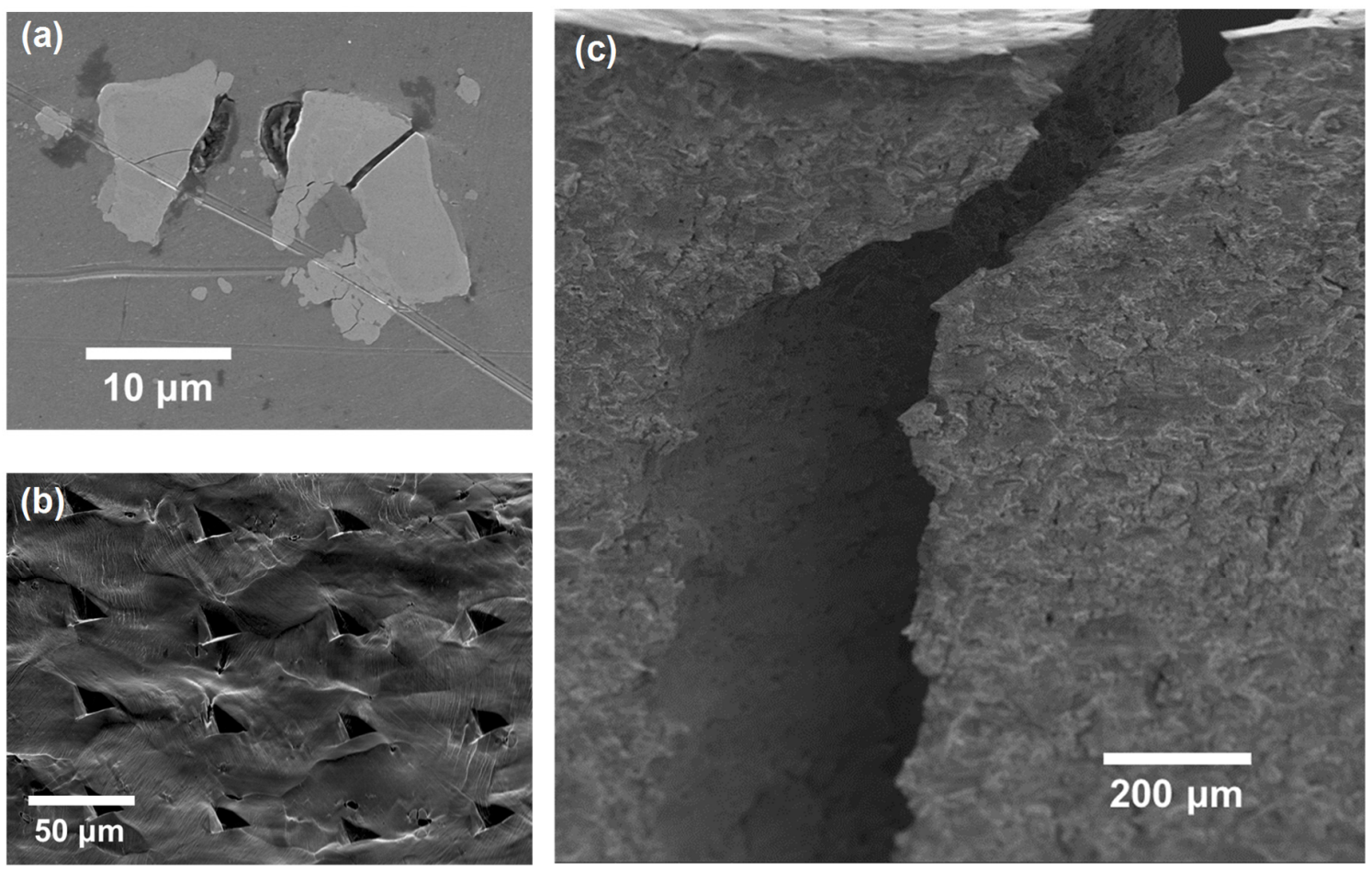

Figure 2: Sample SEM observations of damage mechanisms (a) fractured particle, (b) large out of plane motion and fractures (red circles, and (c) final fracture.

Microstructural changes were monitored during loading to allow for a coupling between the AE activity and material response. Examples of the damage mechanisms, including particle fracture (Figure 2a), out of plane motion effects and slip traces (Figure 2b), as well as final fracture (Figure 2c), monitored during loading with the used setup allow the direct linkage between AE sources and resulting waveforms in this investigation. $\mathrm{AE}$ waveforms were detected and recorded using two PICO sensors with a frequency range from 150 to $750 \mathrm{kHz}$ attached to the specimen in the locations shown in Figure 1a. The AE signals detected by the sensors were preamplified inside the SEM vacuum chamber by a $40 \mathrm{~dB}$ uniform gain across all frequencies. The use of the preamplifiers inside the chamber reduced the effect of any noise sources such as EMI, as previously described by the authors $[5,6,33,46]$. All AE signals were recorded using a PCI-2 data acquisition board with a 
Peak Definition (PDT), Hit Definition (HDT) and Hit Lockout Time (HLT) of 30, 200 and $200 \mu \mathrm{s}$, respectively at a sampling rate of 10 million samples per second (MSPS). All waveforms were bandpass filtered prior to recording between 100 and $1000 \mathrm{kHz}$ which represents the closest setting available in the data acquisition software. Figure $1 \mathrm{~b}$ shows a typical engineering stress-true strain curve obtained by using the average full field strain during loading (as computed by DIC data) overlaid with the $\mathrm{AE}$ data represented via the amplitude distribution.

\subsection{AE Signal Processing Framework}

To attempt the identification of damage mechanism activation in this article, each AE waveform was passed through a digital Butterworth band pass filter, depicted in Figure 3a designed based on the optimum sensor sensitivity range of the sensors used. The results of using the filter are observed when comparing the raw recorded waveform in Figure $3 \mathrm{~b}$ to the filtered waveform in Figure 3c. Hence, the low frequency content below $150 \mathrm{kHz}$ was effectively removed shifting the peak frequency values marked by the circle in the FFT from $140 \mathrm{kHz}$ to approximately $500 \mathrm{kHz}$. After applying the filter, a combination of time and frequency based features identified in ASTM E1316 were extracted to characterize each waveform [66-68]. The extraction was performed using the commercially available NOESIS software (MISTRAS Inc) [69]. The data was then normalized between a minimum value of zero and a maximum of one to account for the effect of variable feature units.

Each feature was subsequently examined using a combination of correlation, variance, and distribution metrics to select a subset of features that fully represented the separation of data in the full feature space with as few features as possible in an objective framework. Unsupervised clustering was then performed using a Gaussian Mixtures Model (GMM) which is more versatile in accounting 
for directionality in data sets. The resulting clusters were coupled with in situ observed microstructural changes to identify those clusters most probable to be representative of noise or specific damage mechanisms such as particle fracture. The identified cluster centers were compared to those obtained in a cyclic loading case to identify noise and similar damage mechanisms present during cyclic loading [10]. Figure 4 shows the overall workflow for the AE signal post processing framework in this article.

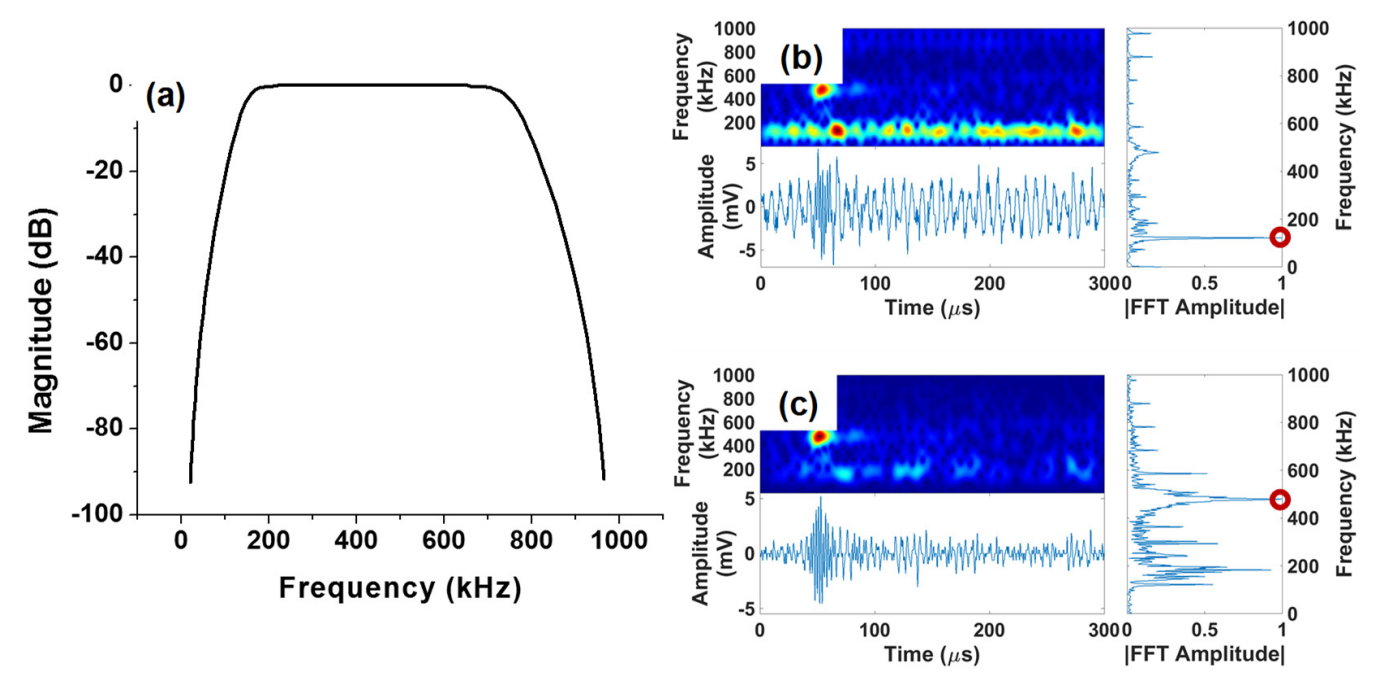

Figure 3: (a) Digital $10^{\text {th }}$ Order Butterworth Filter used, (b) raw AE signal, and (c) filtered AE signal to the sensor range.

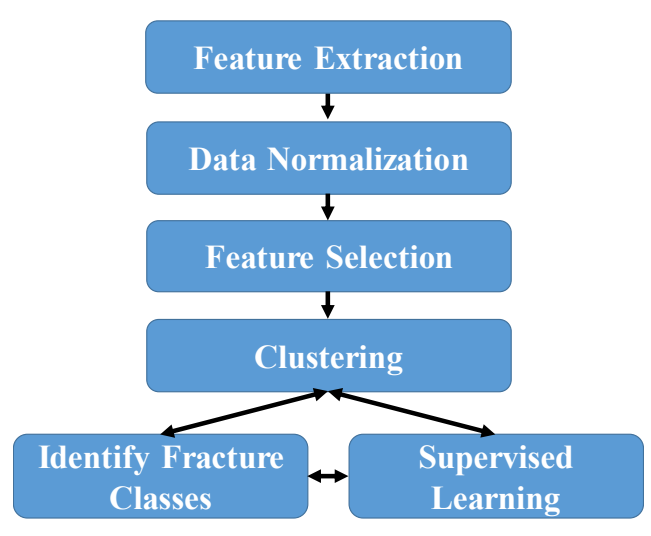

Figure 4: Workflow for AE data post processing. 


\section{Results}

A total of 31 time and frequency based features were extracted from recorded AE datasets similar to the one shown in Figure 1b that corresponds to the tension tests described in section 2 of this article. The features selected were assigned identification numbers ranging from 1 to 31 so they can be identified in the signal processing framework described next and the list is given in the appendix. Note that a more detailed description of these features and their role in monitoring fracture is given in the appendix, as the workflow described in this section does not depend neither on the precise definition nor the number of selected features. Also note that to obtain the results presented in this section only three data sets, two monotonic and one cyclic, obtained using the geometry depicted in Figure 1were used to demonstrate the method in this article. The observed AE waveforms were compared to in situ observations made on this geometry and a sharp notch geometry used previously by the authors $[5,6,46]$. Therefore, the presented analysis, in conjunction with the in situ monitoring of particle fracture has the statistical basis to increase the confidence in the trends observed and conclusions drawn. To ensure that the most consistent data was combined, all data sets used the same AE acquisition settings, however, the procedure discussed here can be used for other materials and geometries. In fact, the in situ monitoring of particle fracture to identify associated AE characteristics were performed on two different geometries [5, 6, 33, 46].

A correlation matrix was generated as shown in Figure 5a. In addition, a covariance matrix was generated and the results are shown in Figure 5b. Feature 1 exists on the lower left corner of each matrix, and the features numerically increase as you move up and right. In general, the correlation matrix is a normalized form of the covariance matrix and it can be used to show the relationship 
between a feature and all other features in a given dataset, while the covariance matrix can be used to examine the spread of values between features. More specifically, the diagonal of the covariance matrix shows the spread of the data within each feature. A large variance was considered in this article to be an indication of the feature's capability to track changes in the recorded AE activity, as different sources were expected to produce sufficiently different values of certain features. At this point, though, this was a hypothesis that the workflow described in this article is targeting to test its validity. Furthermore, the correlation and covariance matrices can be evaluated as the average effect of each feature to all others. Such viewpoint and subsequent analysis was adopted in this article to identify features that under the conditions examined and the particular material and failure mechanism targeted appear to monitor damage evolution.

(a)

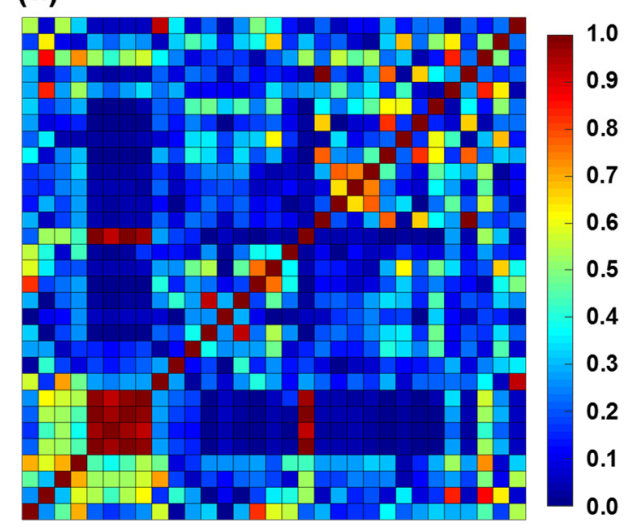

(b)

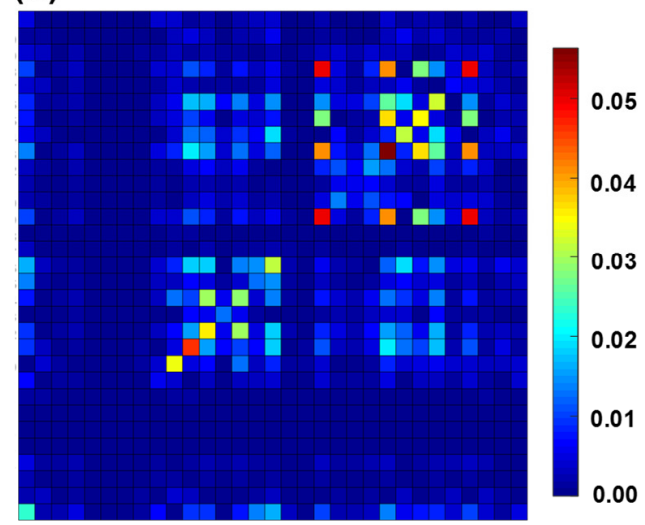

Figure 5: (a) Correlation matrix and (b) covariance matrix for the monotonic load data.

The average response of all features is shown in Figure 6. These average trends of correlation and covariance show almost linear behavior making the selection of a subset of AE features challenging. In this investigation, the appearance of the first inflection point that produced a consistent set of features in all data sets examined was used. In the curve of Figure 6a this corresponds to a correlation 
value of 0.25 and above was used to select the number of features to be used later in the described workflow. Similarly, an inflection point that corresponded to a covariance 0.006 and below was selected [70]. This procedure resulted in the selection of 7 features based on correlation and 3 additional features based on covariance.
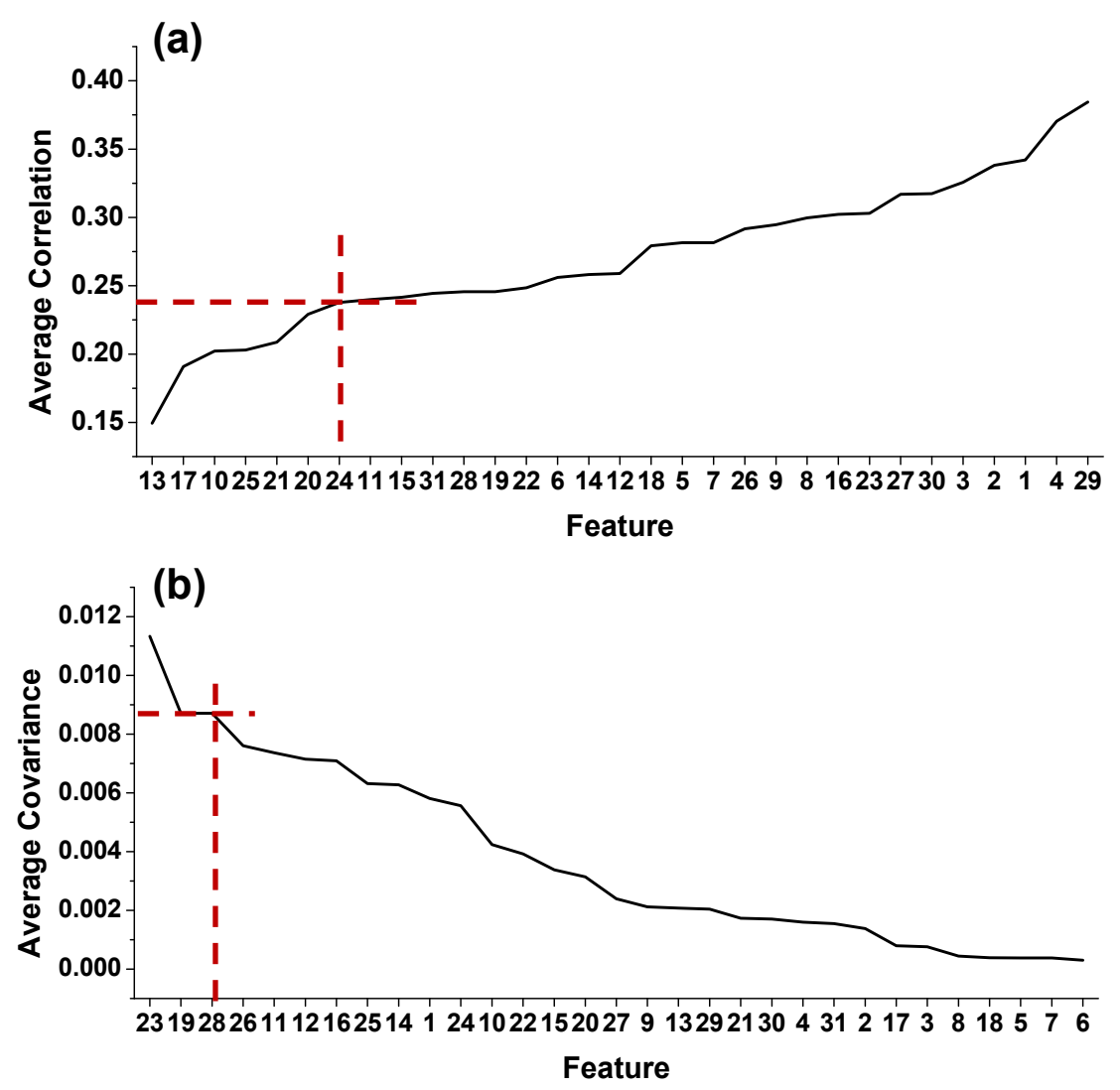

Figure 6: Average (a) correlation and (b) covariance of each feature with respect to all others.

To further validate that the features selected will provide a good basis for further post-processing, histograms of the normalized values within each feature were generated. The criterion adopted in this step was based on the fact that features that show greater spread of values would practically assist in identifying changes in the AE datasets. Examples of resulting histograms are shown in Figure 7 in which each feature is labeled with its corresponding identification number. The features 
displayed in Figure 7 all contain more than one peak and, therefore, they were identified as useful for clustering algorithms. The green box indicates two features in Table 2 that are highly correlated, therefore, only the "peak frequency" was used resulting in a total of nine features.
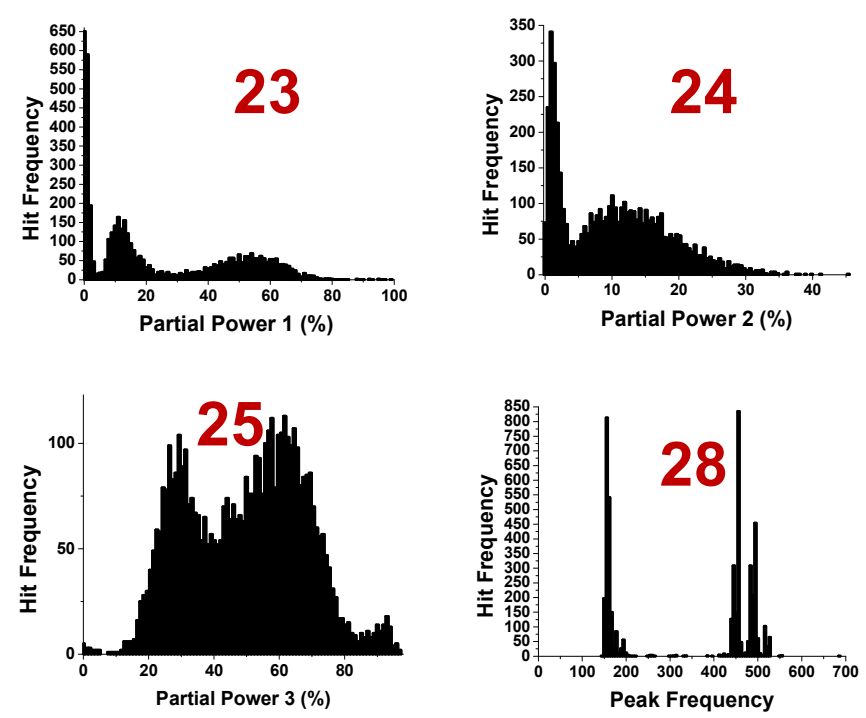

Figure 7: Sample Feature distributions.

Table 2: AE features useful for clustering.

\begin{tabular}{|c|c|c|c|}
\hline \multicolumn{2}{|c|}{$\begin{array}{c}\text { Correlation Based } \\
\text { Features }\end{array}$} & \multicolumn{3}{|c|}{$\begin{array}{c}\text { Variance Based } \\
\text { Features }\end{array}$} \\
\hline 13 & Reverberation Frequency & 23 & Partial Power 1 \\
\hline 17 & Non Dimensional Amplitude & 19 & FFT Peak Frequency \\
\hline 10 & Rise Angle & 28 & Peak Frequency \\
\hline 25 & Partial Power 3 & & \\
\hline 21 & FFT Width @30\% & & \\
\hline 20 & FFT Width @10\% & & \\
\hline 24 & Partial Power 2 & & \\
\hline
\end{tabular}

Unsupervised clustering was performed on the combined monotonic data sets using the identified reduced feature space using a GMM in part to account for any potential directionality in the data set and to account for the natural Gaussian nature of the AE data as observed in Figure 7. The optimum number of clusters was selected based on the Davies Bouldin (DB) and Silhouette (S) 
clustering metrics. The DB metric evaluates the compactness of the resulting clusters while the S metric evaluates the separation between cluster centers. A GMM [71] was used because of its capability to expand differently along each feature vector as opposed to the commonly used k-means clustering method that expands uniformly. Three clusters were identified as the most compact number with the greatest distance between centers by identifying the number of clusters with the minimum $\mathrm{DB}$ value and maximum $\mathrm{S}$ value.

The corresponding clustering results are plotted as a function of strain and overlaid with the load curve for the two datasets shown in Figure 8. The top row shows the results for a specimen loaded to catastrophic failure, while the second row was loaded to approximately $80 \%$ of the ultimate strength allowing identification of final fracture AE by comparing the two set of results. Both specimens show initiation of the AE activity during early loading stages, while two clusters were found to be present throughout the specimen's life. The AE signals in cluster 3 were found to be present only at the time of failure in the first specimen (Figure 8a) while they were not present anywhere in the second specimen (Figure 8b) and are therefore expected to correspond to final fracture. Moreover, the nature of these final failure signals is similar to those obtained during failure of the double-notched specimens used in previous work [33] which further validates that correspond to final failure. The identification of the source for the remaining two clusters required coupling between in situ monitored microscale damage evolution and the AE activity as it was previously attempted by the authors $[5,6,33]$. 

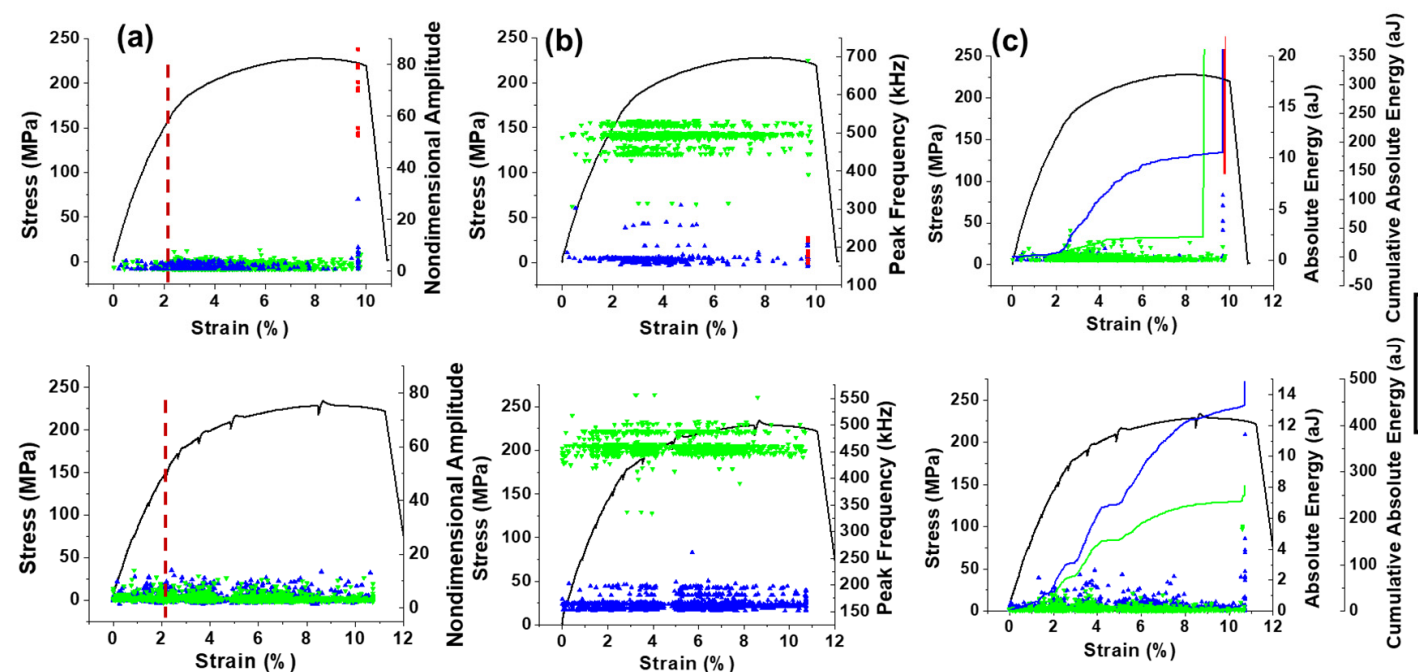

$\Delta$ Cluster 1

Cluster 2

Figure 8: AE signal clustering results as a function of strain overlaid with the load curve for a load to failure (top) and a load to $80 \%$ of the ultimate (bottom) represented as (a) amplitude, (b) peak frequency, and (c) Absolute Energy.

Significant differences in the AE signals that correspond to the three clusters were observed as shown in Figure 9 when plotting features against each other. Specifically, clusters 1 and 2 correspond to AE signals with low amplitude, while cluster three contains AE waveforms with much higher amplitude as expected from a dominant fracture source. Additionally, cluster 2 appears to consist of $\mathrm{AE}$ waveforms that have higher peak frequency compared with clusters 1 and 3 , while cluster 1 was found to contribute the most energy based on the results in Figure 8c. Previous work by the authors [5] showed in almost real time the connection between particle fracture and AE indicating that particle fracture is an instantaneous source represented by burst nature AE signals of a "higher" frequency content, generally between 450 and $550 \mathrm{kHz}$. This information was successfully separated from machine noise, which was identified by applying a small preload well within the elastic regime.

These noise AE signals were found to be of continuous nature with low amplitude and relatively lower frequency content (around $150 \mathrm{kHz}$ ). In summary, based on the results in Figures 8-9, cluster 
1 contains lower frequency AE waveforms with a range of risetime and duration values, while cluster 2 comprises AE signals with higher frequency and more consistent low rise time and duration values indicating burst nature waveforms which agreed with previous work by the authors.
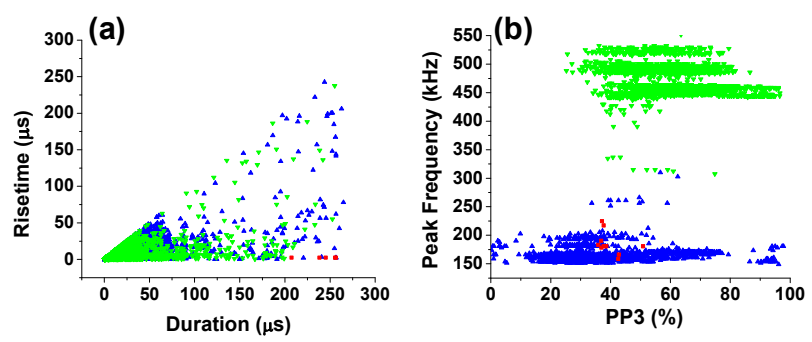

(c)
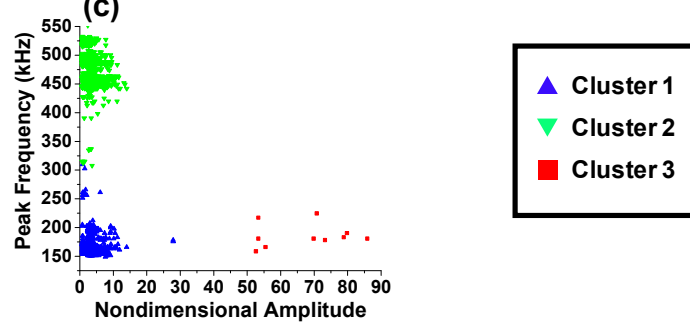

Figure 9: Cluster separation in feature space showing (a) burst nature, (b) frequency nature, and (c) amplitude vs frequency.

\section{Discussion}

To investigate the potential of the AE clustering presented in section 3 to identify damage sources, specific AE characteristics are sought that could be reliably associated with such damage. Previous investigations on the damage processes of $\mathrm{Al} 2024-\mathrm{T} 3$ indicated particle fracture and void nucleation and coalescence to be the dominant sources of damage for this type of alloys [5, 72]. To verify that an uncracked particle inside an aluminum matrix would fracture given the applied loading, Figure 10 shows results from a crystal plasticity finite element analysis (FEA) model that was developed by the authors. Specifically, a rate-independent crystal plasticity formulation for a FCC crystal structure in the form of a user subroutine was employed. The formulation and the development of the user subroutine was originally performed by Anand and Kothari[73]. For the [100] orientation 
considered, eight of the twelve slip systems were activated. The load was applied in the vertical direction. The particle properties were assumed to be linearly elastic and isotropic with elastic modulus and Poisson's ratios found in literature [74] for the case of $\theta$ phase (Al2 Cu, E = 120GPa) particles. The $\mathrm{Al}$ matrix that was investigated was assumed to be in both the hard crystal orientation, the (111) crystal plane normal is aligned with the loading direction, (Figure 10) and the soft [100] crystal orientation, the (100) crystal plane normal is aligned with the loading direction, (Figure 11) to show the localization effects that result from elastic property mismatch and lead to particle fracture. The 3D FEA model had10688 elements and 11963 degrees of freedom and was run under displacement control. In both configurations, the crystal plasticity simulation was stopped at the same stress and was switched to an eXtended Finite Element Framework (XFEM) that used a maximum principal stress criterion to initiate damage. Stress and strain concentrations were observed as the result of the crystal orientation. In both cases, the stress and strain primarily builds near the particle with more pronounced accumulations in the harder orientation shown in Figure 10. Further loading shows that the appearance of damage occurs in the particle near the boundary in the case of the hard orientation, as indicated by the red areas in Figure 10c, while damage occurs in the Aluminum matrix near the boundary as indicated by the corresponding red areas in Figure $11 \mathrm{c}$. 

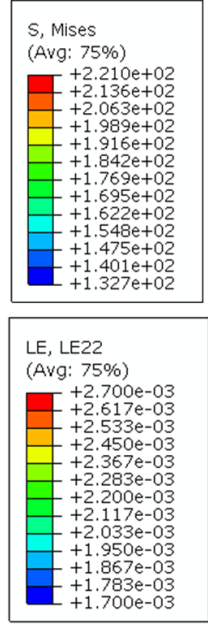

(a)

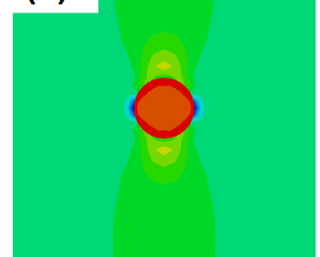

(b)

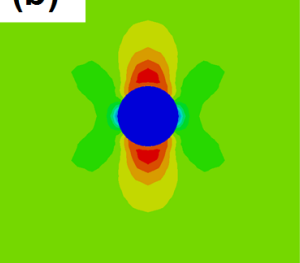

(c)
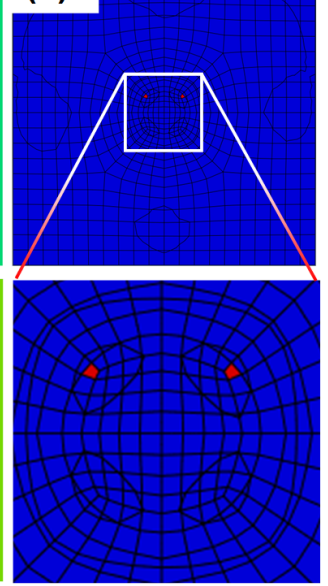

Figure 10: Theoretical particle contribution to (a)stress and (b) strain for an Al matrix oriented with the [111] direction aligned with the loading direction with an $\mathrm{Al} 2 \mathrm{Cu}$ particle embedded. Damage location is shown in (c).
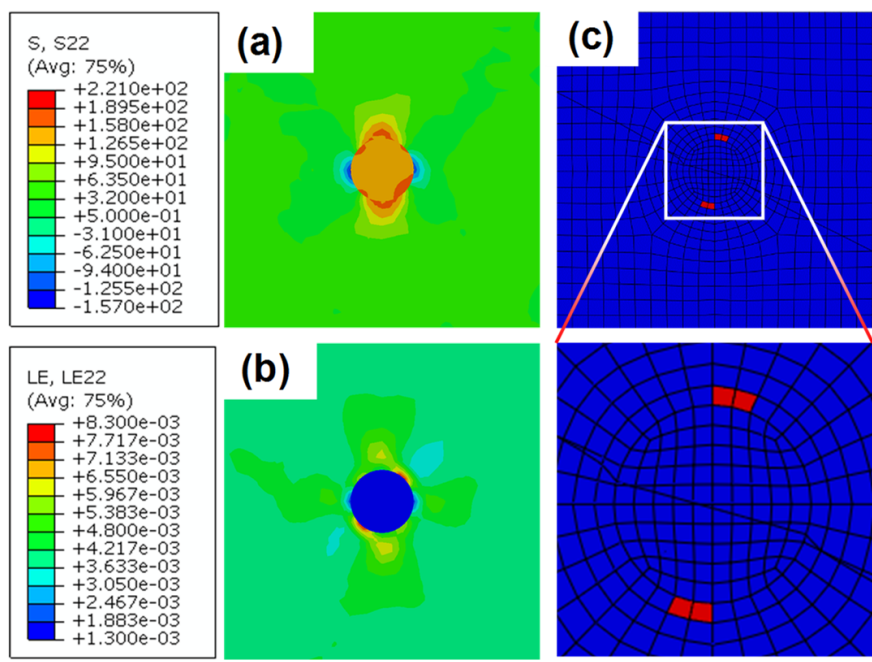

\section{(b)}
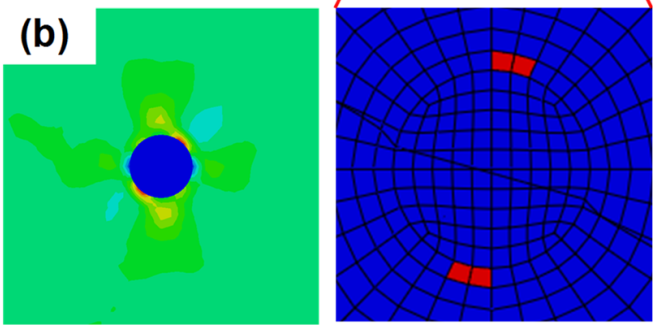

Figure 11: Theoretical particle contribution to (a)Stress and (b) strain for an Al matrix oriented with the [100] direction aligned with the loading direction with an $\mathrm{Al} 2 \mathrm{Cu}$ particle embedded. Damage location is shown in (c).

Considering the number of particles present in the material as well as the number of grains, a large number of possible combinations of particle and surrounding matrix property can indeed induce conditions that result in particle fractures suggesting a large number of damage signals would be expected from such mechanisms. Both clusters 1 and 2 contain a large number of signals throughout 
the load and could be the result of such sources. Both particle fracture and dislocation motion occur at the microscale and therefore they were expected to correspond to AE signals with relatively low amplitude values. Thus, to determine the possibility to actually record AE that results from damage mechanisms such as particle fracture, a set of nanoindentations was performed directly on a particle while recording $\mathrm{AE}$ activity. In this case, the indentation was performed to a depth of $4 \mu \mathrm{m}$ to ensure the particle would fracture. A burst nature AE activity shown in Figure 12a was recorded along with the crack growing from the tip of the indentation. Moreover, this AE signal has a peak frequency of $550 \mathrm{kHz}$ and an amplitude 10 times higher than the noise level. The same indentation procedure was applied on a region without a particle for comparison. The AE activity observed comprised signals with amplitude within the noise floor and peak frequency occurred around 300 kHz as shown in Figure 12b.
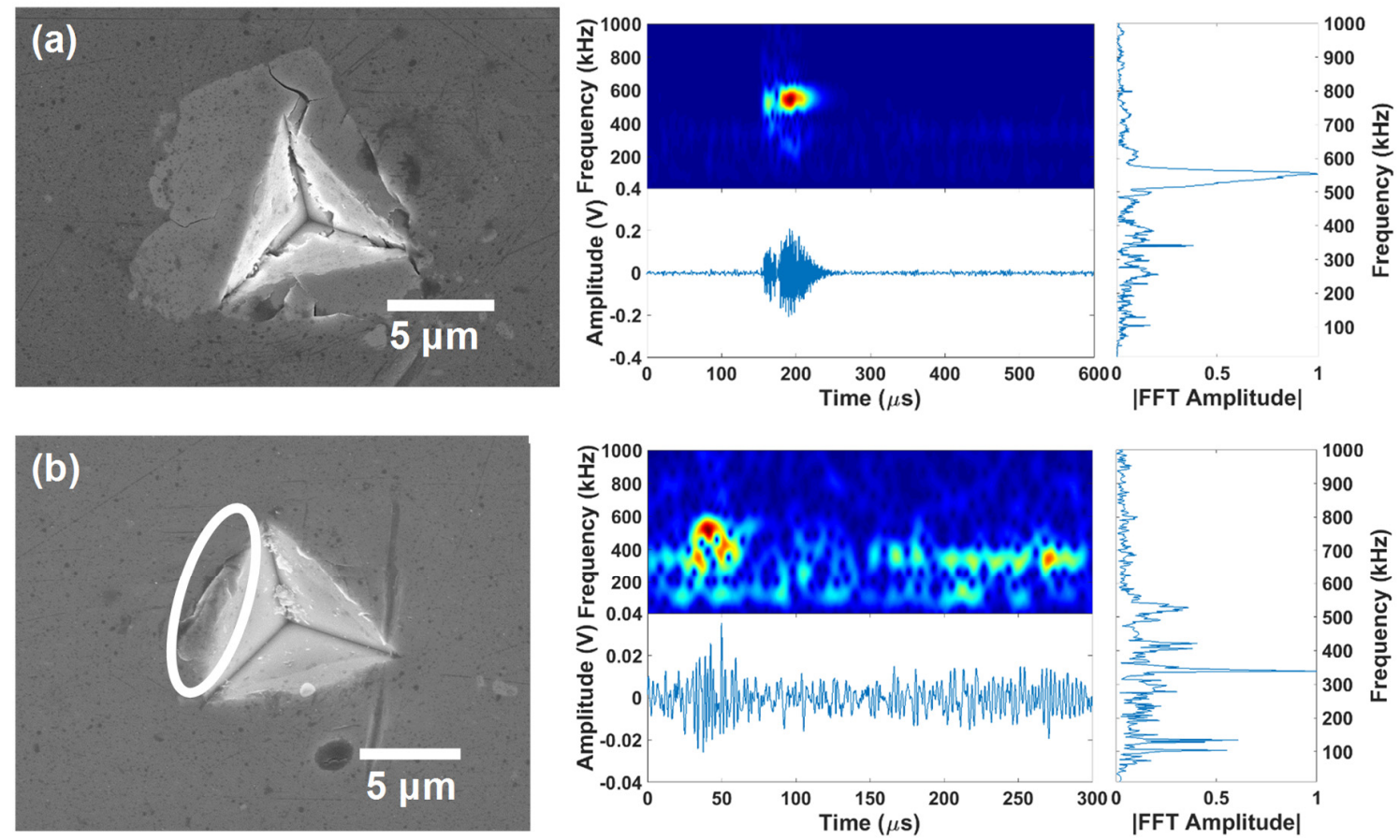

Figure 12 Nanoindentation and corresponding recorded AE on (a) a particle that fractures, and (b) an area with no particle. 
Examples of $\mathrm{AE}$ waveforms that correspond to the different clusters along with an example of a waveform determined to indicate particle fracture via in situ SEM testing are shown in Figure 13. Signals in cluster 1, depicted in Figure 13a, were found to be continuous in nature with low amplitude and frequency, while the waveforms in cluster 2 shown in Figure 13b, were found to be of low amplitude but burst in nature with a "higher" frequency content. Furthermore, Figure 13b and Figure 13d show similar waveforms, both of which have characteristics that are comparable to the waveform in Figure 12a. Figure 13d was observed at the time of particle fracture during in situ SEM monitoring suggesting that cluster 2 represents early damage and possible particle fracture. Figure 12c shows an example of final fracture AE signal that corresponds to cluster 3; it was found that it has fast risetime similar to cluster 2 and the in situ observed particle fracture signal, providing further support that both clusters 2 and 3 represent fracture events.

(a)

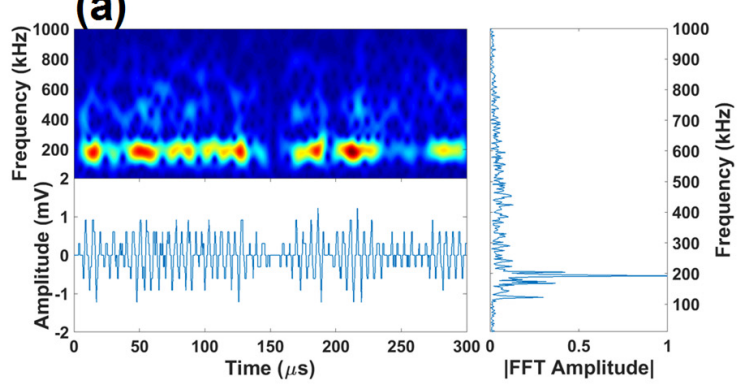

(b)

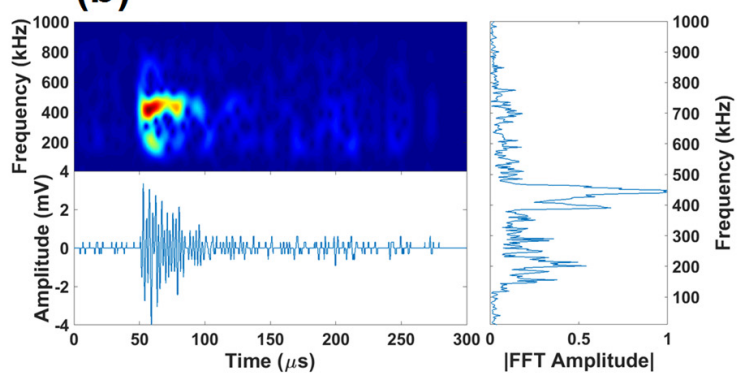

(c)

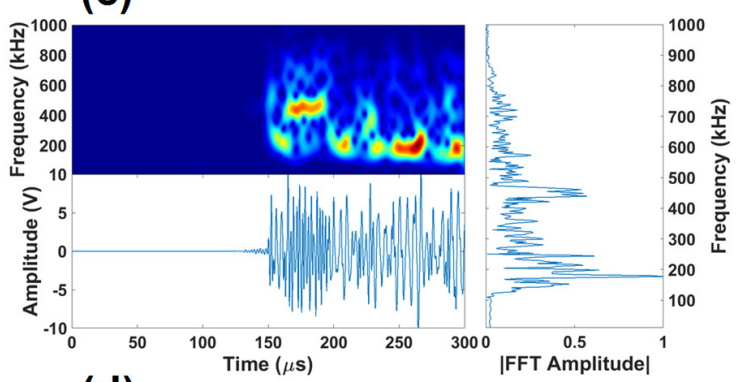

(d)

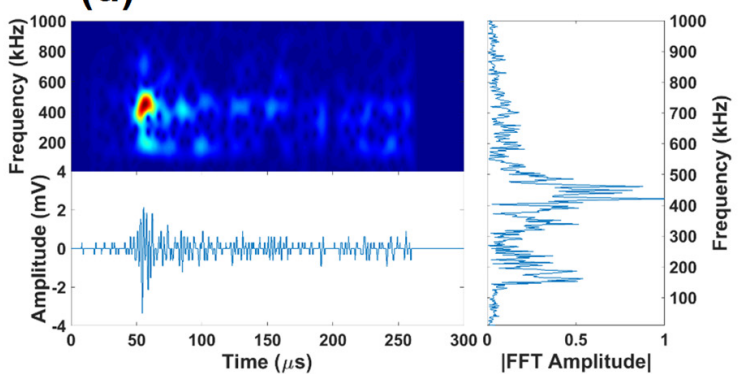

Figure 12: Sample Cluster Waveforms (a) Cluster 1, (b) Cluster 2, (c) Cluster 3, and (d) waveform of particle fracture identified by in situ SEM monitoring. 
Considering that clusters 1 and 2 were observed throughout the tests, it was further expected that these sources are either the result of early non-catastrophic damage sources, such as those discussed previously, or noise. Therefore, leveraging previous work by the authors that targeted the recordings of $\mathrm{AE}$ from inside the SEM and the $\mathrm{AE}$ results obtained from fracturing particles from nanoindentation, it is possible to compare the average value of each of the features for each of the clusters in this article to the value of the features from those AE signals found to be the result of particle fracture. Table 2 shows such values for all clusters. Clusters 1 and 2 contain the majority of recorded AE signals with only a few in cluster 3 as expected for the final fracture cluster where only a few large crack sources and reflections are possible at the point of failure. Based on the comparison of the results from this article with the previous work by the authors, it is concluded that only cluster 2 has the burst nature and frequency content that matches the frequency content of the in situ observed and nanoindentation particle facture AE events. It should be noted that this frequency content comparison was based on several AE features including: peak frequency, partial power 1, 2 and 3, FFT width at 30\% and reverberation frequency (a complete definition of all AE features in this article is given in the Appendix to assist the evaluation of the signal processing workflow shown in this article). Furthermore, cluster 2 shows similar duration compared with the in situ $[5,6]$ and nanoindentation induced particle fracture observations. Cluster 3 shares the burst nature and some frequency characteristics of the particle fracture suggesting this cluster is also the result of a fracture event, though on a larger scale as discussed previously (see Table 3). 
Table 3: Characteristics of PF from in situ observation compared to average and range of each cluster.

\begin{tabular}{|c|c|c|c|c|c|}
\hline Feature & $\begin{array}{c}\text { In Situ } \\
\text { Particle Fracture }\end{array}$ & $\begin{array}{c}\text { Nanoidnetation } \\
\text { Particle Fracture }\end{array}$ & $\begin{array}{c}\text { Cluster 1 } \\
\text { (1933 Hits) }\end{array}$ & $\begin{array}{c}\text { Cluster 2 } \\
\text { (2828 Hits) }\end{array}$ & $\begin{array}{c}\text { Cluster 3 } \\
\text { (10 Hits) }\end{array}$ \\
\hline Nondimensional Amplitude & 3.43 & 29 & $67.3 \pm 1.5$ & $3.0 \pm 1.7$ & $3.2 \pm 12.6$ \\
\hline Peak Frequency $(\mathrm{kHz})$ & 476 & 554 & $186.0 \pm 12.9$ & $474.1 \pm 25.5$ & $164.7 \pm 20.5$ \\
\hline Duration ( $\mu \mathrm{s})$ & 22 & 63 & $48 \pm 43.7$ & $26 \pm 132.9$ & $248 \pm 15.8$ \\
\hline Rise Angle (rad) & 1.414 & 1.342 & $1.6 \pm 0.3$ & $0.3 \pm 0.3$ & $0.2 \pm 0.0$ \\
\hline Partial Power 1 & 9.5 & 0.5 & $0 \pm 21$ & $9 \pm 8$ & $46 \pm 0.01$ \\
\hline Partial Power 2 & 24 & 9 & $0.3 \pm 6.1$ & $11 \pm 9.2$ & $10 \pm 0.04$ \\
\hline Partial Power 3 & 64 & 89 & $40 \pm 15$ & $61 \pm 12$ & $35 \pm 5$ \\
\hline FFT Width @30\% & 393 & 230.7 & $661 \pm 83$ & $421 \pm 86$ & $409 \pm 29$ \\
\hline Reverberation Frequency & 147 & 493 & $150 \pm 77$ & $99 \pm 33$ & $106 \pm 52$ \\
\hline RA Value & 0.03 & 0.5 & $0.03 \pm 0.81$ & $0.3 \pm 0.6$ & $0.6 \pm 0.00$ \\
\hline
\end{tabular}

The same processing framework was used to post-process AE signals obtained during cyclic loading.

In this case, the loading was halted prior to final failure resulting in only early fracture activity such as particle fracture and no final fracture events. Using the same method and features identified in Table 2, the AE data was separated into 3 distinct clusters using the same unsupervised clustering procedure discussed for the monotonic loading case. The results of the clustering are shown in Figure 11 and are displayed as a function of cycle. Clusters 1 and 2 were found to be similar to the monotonic case. Therefore, cluster 1 contains AE signals with relatively lower amplitude and peak frequency and generally larger duration values compared with cluster 2. Cluster 2, shares characteristics of the corresponding cluster in the monotonic loading conditions including burst nature and "higher" frequency content. The large spike in activity at the $10^{\text {th }}$ cycle corresponds to additional activity that occurred when the specimen was removed from the load cell for microscopy before being returned to the loading stage for further cycling. In this case cluster 3 does not represent the presence of final fracture, but rather a set of signals that are much higher in amplitude 
as would be expected of a final fracture signals, but contains much lower frequency content and are more continuous in nature. As the clustering performed was unsupervised it is not expected that this cluster would represent the same source as was the case for the monotonic loading condition and considering the cyclic nature of the loading may be the result of a fatigue source such as fretting.

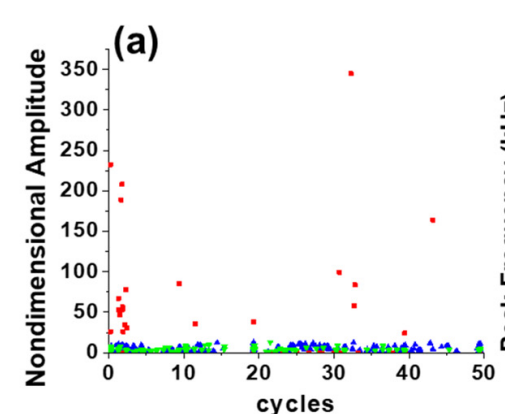

(b)
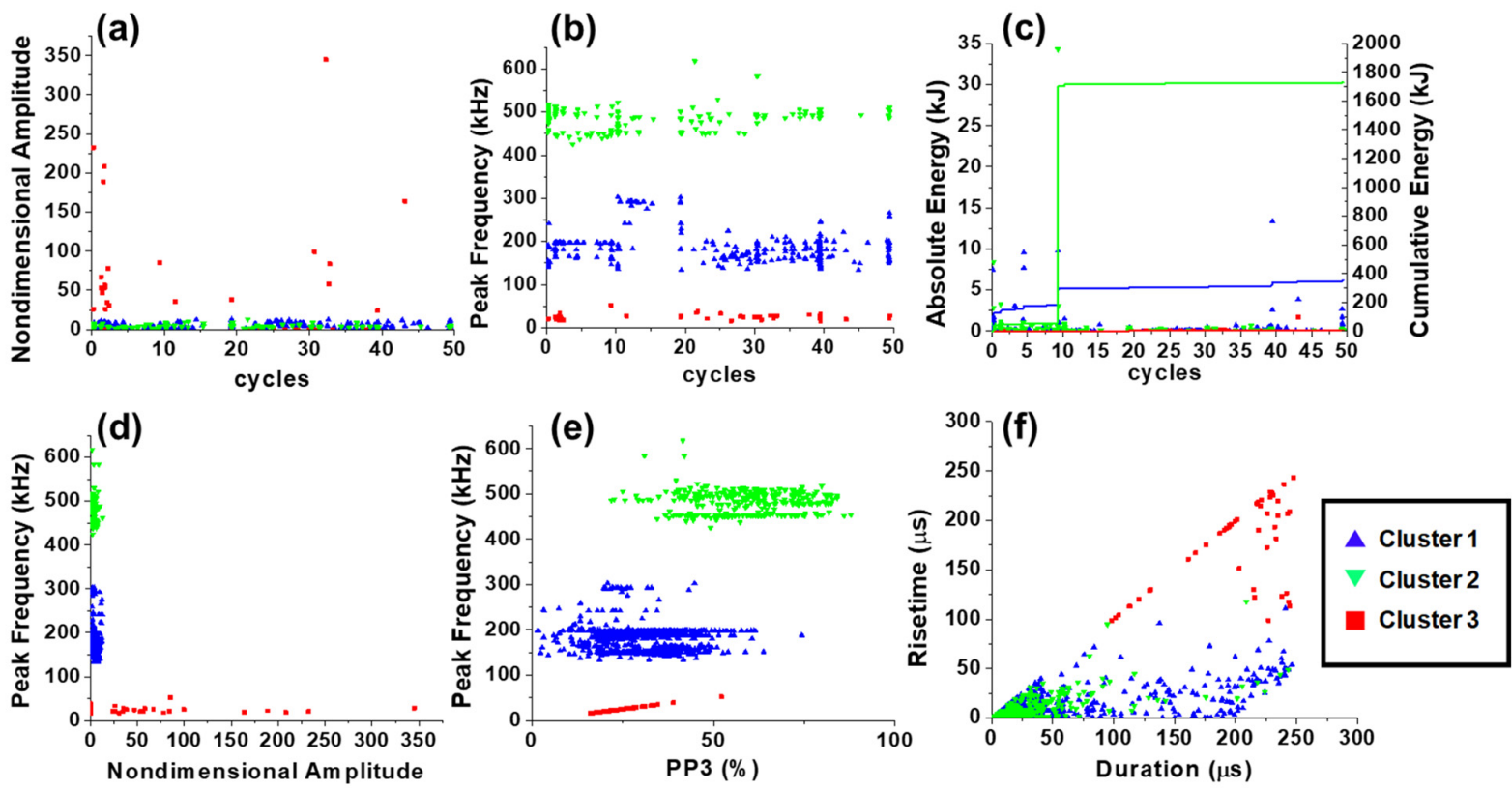

Figure 13: Unsupervised clustering results of a cyclic loading test. (a) Non-dimensional amplitude, (b) peak frequency, and (c) absolute energy as a function of the applied cycle. The same AE data is shown to separate when plotting (d) amplitude vs frequency, (e) frequency vs partial power 3, and (f) the burst nature of the $\mathrm{AE}$ waveforms.

\section{Conclusion}

A signal post processing framework was presented in this article to investigate the potential of the acoustic emission method to monitor fracture. To collect appropriate data AE controlled experiments including both inside the scanning electron microscope and in a nanoindentation setup, targeted the activation of fracture mechanisms inherent to aluminum 2024. Moreover, the contribution of local microstructure to the initiation of damage mechanisms was verified by a crystal 
plasticity finite element model. To account for the large amount of data that is generated and provide a method to link each $\mathrm{AE}$ waveform to a potential fracture source, the proposed data post processing framework objectively reduces the number of features required to represent the acoustic emission activity. The resulting data clusters were examined in relation to in situ SEM and nanoindentation observed sources to identify clusters indicative of damage including final fracture as well as particle fracture. Overall, it was argued that it is the combination of such post processing framework with in situ and small scale experiments that makes this approach both novel and applicable to a broad range of materials. To this effect, only AE signals that can be linked with a particular damage mechanism using such controlled in situ experiments are able to be identified by this method.

\section{Acknowledgements}

A. Kontsos would like to acknowledge the financial support received by the Office of Naval Research under the Young Investigator Program, Award \#N00014-14-1-0571. 


\section{Appendix - AE Feature Definitions}

\begin{tabular}{|c|c|c|}
\hline ID & Feature & Definition \\
\hline 1 & Duration $(\mathrm{FX})$ & Time difference between the last threshhold crossings \\
\hline 2 & Amplitude & Peak voltage of the AE waveform \\
\hline 3 & Counts to Peak & Cycles from signal start to max amplitude \\
\hline 4 & Counts & Cycles from signal start to end \\
\hline 5 & Energy & Energy Counts \\
\hline 6 & Absolute Energy & Signal Energy \\
\hline 7 & Signal Strength & Area under signal envelope \\
\hline 8 & Amplitude $\mathrm{mV}$ & Max signal Amplitude in $\mathrm{mV}$ \\
\hline 9 & Risetime & Time from signal start to max amplitude \\
\hline 10 & Rise Angle & Angle from start to max amplitude \\
\hline 11 & Decay Angle & Angle from signal end to max amplitude \\
\hline 12 & Average Frequency & Average Frequency \\
\hline 13 & $\begin{array}{l}\text { Reverberation } \\
\text { Frequency }\end{array}$ & Average frequency form max amplitude to end of signal \\
\hline 14 & Initiation Frequency & Average Frequency from signal start to max amplitude \\
\hline 15 & Zero Crossings & Number of zero crossings from signal start to end \\
\hline 16 & $\begin{array}{l}\text { Zero Crossings } \\
\text { Frequency }\end{array}$ & Average Frequency based on zero crossings \\
\hline 17 & $\begin{array}{l}\text { Non Dimensional } \\
\text { Amplitude }\end{array}$ & Ratio of max to mean signal amplitude \\
\hline 18 & FFT Amplitude & Max amplitude of FFT magnitude \\
\hline 19 & FFT Peak Frequency & Peak Frequency based on FFT \\
\hline 20 & FFT Width@10\% & Bandwidth over $10 \%$ of the max amplitude \\
\hline 21 & FFT Width@, $30 \%$ & Bandwidth over $30 \%$ of the max amplitude \\
\hline 22 & FFT Crossings@30\% & FFT magnitude at $30 \%$ max amplitude crossings \\
\hline 23 & Partial Power 1 & $\begin{array}{c}\text { The ratio of the sum of the power in the spectrum from } 0 \text { to } 200 \mathrm{kHz} \text { over the total } \\
\text { power in the entire frequency range }\end{array}$ \\
\hline 24 & Partial Power 2 & $\begin{array}{l}\text { The ratio of the sum of the power in the spectrum from } 200 \text { to } 400 \mathrm{kHz} \text { over the total } \\
\text { power in the entire frequency range }\end{array}$ \\
\hline 25 & Partial Power 3 & $\begin{array}{l}\text { The ratio of the sum of the power in the spectrum from } 400 \text { to } 6400 \mathrm{kHz} \text { over the total } \\
\text { power in the entire frequency range }\end{array}$ \\
\hline 26 & Partial Power 4 & $\begin{array}{c}\text { The ratio of the sum of the power in the spectrum from } 600 \text { to } 800 \mathrm{kHz} \text { over the total } \\
\text { power in the entire frequency range }\end{array}$ \\
\hline 27 & Frequency Centroid & \\
\hline 28 & Peak Frequency & The frequency corresponding to the maximum power in the power spectrum \\
\hline 29 & Peak Power & Maximum Power determined from FFT power spectrum \\
\hline 30 & Threshold & Dynamic threshold determined from peak amplitude \\
\hline 31 & RA Value & ratio between risetime and amplitude \\
\hline
\end{tabular}




\section{References}

[1] Bassim MN, Lawrence SS, Liu CD. Detection of the onset of fatigue crack growth in rail steels using acoustic emission. Engineering Fracture Mechanics. 1994;47:207-14.

[2] McBride S, MacLachlan J, Paradis B. Acoustic emission and inclusion fracture in 7075 aluminum alloys. Journal of Nondestructive Evaluation. 1981;2:35-41.

[3] Ono K, Huang Q. Dynamic Characterization Of Composite Fracture Mechanisms With Pattern Recognition Of Acoustic Emission Signals. Proc 8th CIMTEC, Forum on New Materials, Florence, Italy1994.

[4] Vanniamparambil PA, Cuadra J, Guclu U, Bartoli I, Kontsos A. Cross-validated detection of crack initiation in aerospace materials. 2014. p. 906411-29.

[5] Wisner B, Kontsos A. In situ monitoring of particle fracture in aluminium alloys. Fatigue \& Fracture of Engineering Materials \& Structures. 2017.

[6] Wisner B, Kontsos A. Investigation of Particle Fracture during Fatigue of Aluminum 2024. International Journal of Fatigue. 2018.

[7] Cuadra J, Vanniamparambil P, Servansky D, Bartoli I, Kontsos A. Acoustic emission source modeling using a data-driven approach. Journal of Sound and Vibration. 2015;341:222-36.

[8] Vanniamparambil Pa, Bartoli I, Hazeli K, Cuadra J, Schwartz E, Saralaya R, et al. An integrated structural health monitoring approach for crack growth monitoring. Journal of Intelligent Material Systems and Structures. 2012;23:1563-73.

[9] Carmi R, Vanniamparambil PA, Cuadra J, Hazeli K, Rajaram S, Guclu U, et al. Acoustic Emission and Digital Image Correlation as Complementary Techniques for Laboratory and Field Research. In: Shen G, Wu Z, Zhang J, editors. Advances in Acoustic Emission Technology: Springer New York; 2015. p. 605-22.

[10] Farhidzadeh A, Salamone S, Singla P. A probabilistic approach for damage identification and crack mode classification in reinforced concrete structures. Journal of Intelligent Material Systems and Structures. 2013;24:1722-35. 
[11] Aggelis DG, Kordatos EZ, Matikas TE. Acoustic emission for fatigue damage characterization in metal plates. Mechanics Research Communications. 2011;38:106-10.

[12] Wisner B, Kontsos A. Fatigue Damage Precursor Identification Using Nondestructive Evaluation Coupled with Electron Microscopy. Fracture, Fatigue, Failure and Damage Evolution, Volume 8: Springer; 2017. p. 1-8.

[13] Baram J, Rosen M. Acoustic emission generated during the tensile testing of aluminium alloys. Materials Science and Engineering. 1979;40:21-9.

[14] Chung J-B, Kannatey-Asibu E. Acoustic emission from plastic deformation of a pure single crystal. Journal of Applied Physics. 1992;72:1812.

[15] Cousland SM, Scala C. Acoustic emission during the plastic deformation of aluminium alloys 2024 and 2124. Materials Science and Engineering. 1983;57:23-9.

[16] Meriaux J, Boinet M, Fouvry S, Lenain JC. Identification of fretting fatigue crack propagation mechanisms using acoustic emission. Tribology International. 2010;43:2166-74. [17] Mo C, Wisner B, Cabal M, Hazeli K, Ramesh K, El Kadiri H, et al. Acoustic Emission of Deformation Twinning in Magnesium. Materials. 2016;9:662.

[18] Mukherjee A, Hamstad M, Bianchetti R. Origin of burst-type acoustic emission in unflawed 7075-T6 aluminum. Journal of Testing and Evaluation. 1976;4:313-8.

[19] Roberts TM, Talebzadeh M. Fatigue life prediction based on crack propagation and acoustic emission count rates. Journal of Constructional Steel Research. 2003;59:679-94.

[20] Vanniamparambil P, Guclu U, Kontsos A. Identification of crack initiation in aluminum alloys using acoustic emission. Experimental Mechanics. 2015;55:837-50.

[21] Behnia A, Ranjbar N, Chai HK, Masaeli M. Failure prediction and reliability analysis of ferrocement composite structures by incorporating machine learning into acoustic emission monitoring technique. Construction and Building Materials. 2016;122:823-32.

[22] Bentahar M, El Guerjouma R. Monitoring progressive damage in polymer-based composite using nonlinear dynamics and acoustic emission. The Journal of the Acoustical Society of America. 2009;125:EL39-44. 
[23] Carpenter S, Gorman M. A comparison of AE measurements from aluminum alloys and glass/epoxy composites with different AE techniques. Review of Progress in Quantitative Nondestructive Evaluation: Springer; 1998. p. 509-16.

[24] Cuadra J, Vanniamparambil PA, Hazeli K, Bartoli I, Kontsos A. Damage quantification in polymer composites using a hybrid NDT approach. Composites Science and Technology. 2013;83:11-21.

[25] Castaneda N, Wisner B, Cuadra J, Amini S, Kontsos A. Investigation of the Z-binder role in progressive damage of 3D woven composites. Composites Part A: Applied Science and Manufacturing. 2017;98:76-89.

[26] Gutkin R, Green CJ, Vangrattanachai S, Pinho ST, Robinson P, Curtis PT. On acoustic emission for failure investigation in CFRP: Pattern recognition and peak frequency analyses. Mechanical Systems and Signal Processing. 2011;25:1393-407.

[27] Loutas TH, Kostopoulos V. Health monitoring of carbon/carbon, woven reinforced composites. Damage assessment by using advanced signal processing techniques. Part I: Acoustic emission monitoring and damage mechanisms evolution. Composites Science and Technology. 2009;69:265-72.

[28] Ramirez-Jimenez CR, Papadakis N, Reynolds N, Gan TH, Purnell P, Pharaoh M. Identification of failure modes in glass/polypropylene composites by means of the primary frequency content of the acoustic emission event. Composites Science and Technology. 2004;64:1819-27.

[29] Althoey F, Wisner B, Kontsos A, Farnam Y. Cementitious materials exposed to high concentration of sodium chloride solution: Formation of a deleterious chemical phase change. Construction and Building Materials. 2018;167:543-52.

[30] Farhidzadeh A, Mpalaskas AC, Matikas TE, Farhidzadeh H, Aggelis DG. Fracture mode identification in cementitious materials using supervised pattern recognition of acoustic emission features. Construction and Building Materials. 2014;67:129-38.

[31] Roberts TM, Talebzadeh M. Acoustic emission monitoring of fatigue crack propagation. Journal of Constructional Steel Research. 2003;59:695-712. 
[32] Wang Q, Chu F. EXPERIMENTAL DETERMINATION OF THE RUBBING LOCATION BY MEANS OF ACOUSTIC EMISSION AND WAVELET TRANSFORM. Journal of Sound and Vibration. 2001;248:91-103.

[33] Wisner B, Cabal M, Vanniamparambil P, Hochhalter J, Leser W, Kontsos A. In situ microscopic investigation to validate acoustic emission monitoring. Experimental Mechanics. 2015;55:1705-15.

[34] Builo SI. Correlation between acoustic emission parameters of a growing crack, the stress intensity factor, and the type of stressed state. Russian Journal of Nondestructive Testing. 2006;42:181-4.

[35] Scala C, Cousland SM. Acoustic emission during fatigue crack propagation in the aluminium alloys 2024 and 2124. Materials Science and Engineering. 1983;61:211-8.

[36] Tittmann BR, Buck O. Fatigue lifetime prediction with the aid of SAW NDE. Journal of Nondestructive Evaluation. 1980;1:123-36.

[37] Yu J, Ziehl P, Zárate B, Caicedo J. Prediction of fatigue crack growth in steel bridge components using acoustic emission. Journal of Constructional Steel Research. 2011;67:1254-60. [38] Zárate Ba, Asce M, Caicedo JM, Yu J, Ziehl P. Probabilistic Prognosis of Fatigue Crack Growth Using Acoustic Emission Data. 2012:1101-11.

[39] Sause MGR, Gribov A, Unwin AR, Horn S. Pattern recognition approach to identify natural clusters of acoustic emission signals. Pattern Recognition Letters. 2012;33:17-23.

[40] Hazeli K, Cuadra J, Vanniamparambil P, Kontsos A. In situ identification of twin-related bands near yielding in a magnesium alloy. Scripta Materialia. 2013;68:83-6.

[41] Eleftheroglou N, Loutas T. Fatigue damage diagnostics and prognostics of composites utilizing structural health monitoring data and stochastic processes. Structural Health Monitoring. $2016 ; 15: 473-88$.

[42] Kung C, Fine M. Fatigue crack initiation and microcrack growth in 2024-T4 and 2124-T4 aluminum alloys. Metallurgical Transactions A. 1979;10:603-10.

[43] Payne J, Welsh G, Christ RJ, Nardiello J, Papazian JM. Observations of fatigue crack initiation in 7075-T651. International Journal of Fatigue. 2010;32:247-55. 
[44] Khan F, Bartoli I, Rajaram S, Vanniamparambil PA, Kontsos A, Bolhassani M, et al. Acoustics and temperature based NDT for damage assessment of concrete masonry system subjected to cyclic loading. 2014. p. 90630B-B-10.

[45] Hazeli K, Askari H, Cuadra J, Streller F, Carpick RW, Zbib HM, et al. Microstructuresensitive investigation of magnesium alloy fatigue. International Journal of Plasticity. 2015;68:5576.

[46] Wisner BJ. Damage Precursor Identification via Microstructure-Sensitive Nondestructive Evaluation: Drexel University; 2017.

[47] Loutas T, Vavouliotis A, Karapappas P, Kostopoulos V. Fatigue damage monitoring in carbon fiber reinforced polymers using the acousto-ultrasonics technique. Polymer Composites. 2010;31:1409-17.

[48] Bartali AE, Aubin V, Degallaix S. Surface observation and measurement techniques to study the fatigue damage micromechanisms in a duplex stainless steel. International Journal of Fatigue. 2009;31:2049-55.

[49] Rajaram S, Vanniamparambil PA, Khan F, Bolhassani M, Koutras A, Bartoli I, et al. Fullfield deformation measurements during seismic loading of masonry buildings. Structural Control and Health Monitoring. 2016:n/a-n/a.

[50] Bian G, Chen Y, Hu J, Yang M. Research on model of fatigue microcrack-nucleating in aluminum alloy. The Proceedings of 2011 9th International Conference on Reliability, Maintainability and Safety. 2011:416-9.

[51] Boehlert CJ, Cowen CJ, Tamirisakandala S, McEldowney DJ, Miracle DB. In situ scanning electron microscopy observations of tensile deformation in a boron-modified $\mathrm{Ti}-6 \mathrm{Al}-4 \mathrm{~V}$ alloy. Scripta Materialia. 2006;55:465-8.

[52] Gao M, Feng C, Wei RP. An analytical electron microscopy study of constituent particles in commercial 7075-T6 and 2024-T3 alloys. Metallurgical and Materials Transactions A. 1998;29:1145-51. 
[53] He X-H, Shi H-J, Zhang Y-D, Fu W-X, Yang Z-G, Wilkinson CE. In-situ scanning electron microscopy studies of small fatigue crack growth in ultrasonic consolidation bonded aluminum 2024 laminated structure. Materials Letters. 2013;112:47-50.

[54] May a, Belouchrani Ma, Manaa a, Bouteghrine Y. Influence of fatigue damage on the mechanical behaviour of 2024-T3 aluminum alloy. Procedia Engineering. 2011;10:798-806. [55] Shao H, Zhao Y, Ge P, Zeng W. In-situ SEM observations of tensile deformation of the lamellar microstructure in TC21 titanium alloy. Materials Science and Engineering A. 2013;559:515-9.

[56] Bi H, Li Z, Hu D, Toku-Gyamerah I, Cheng Y. Cluster analysis of acoustic emission signals in pitting corrosion of low carbon steel. Materialwissenschaft und Werkstofftechnik. 2015;46:736-46. [57] Jiang P, Zhang L, Li W, Wang X. Pattern Recognition for Acoustic Emission Signals of Offshore Platform T-Tube Damage Based on K-means Clustering. Advances in Acoustic Emission Technology: Springer; 2017. p. 53-61.

[58] Sibil A, Godin N, R'Mili M, Maillet E, Fantozzi G. Optimization of Acoustic Emission Data Clustering by a Genetic Algorithm Method. Journal of Nondestructive Evaluation. 2012;31:169-80. [59] Elsley R, Graham L. Pattern recognition in acoustic emission experiments. Pattern Recognition and Acoustical Imaging: International Society for Optics and Photonics; 1987. p. 28593.

[60] Rajendra D, Knighton T, Esterline A, Sundaresan MJ. Physics based classification of acoustic emission waveforms. SPIE Smart Structures and Materials+ Nondestructive Evaluation and Health Monitoring: International Society for Optics and Photonics; 2011. p. 79833H-H-8. [61] Sause MG, Horn S. Quantification of the uncertainty of pattern recognition approaches applied to acoustic emission signals. Journal of Nondestructive Evaluation. 2013;32:242-55.

[62] Baccar D, Söffker D. Identification and classification of failure modes in laminated composites by using a multivariate statistical analysis of wavelet coefficients. Mechanical Systems and Signal Processing. 2017;96:77-87.

[63] Ince NF, Kao C-S, Kaveh M, Tewfik A, Labuz JF. A machine learning approach for locating acoustic emission. EURASIP Journal on Advances in Signal Processing. 2010;2010:895486. 
[64] Loutas T, Eleftheroglou N, Zarouchas D. A data-driven probabilistic framework towards the in-situ prognostics of fatigue life of composites based on acoustic emission data. Composite Structures. 2017;161:522-9.

[65] Kostopoulos V, Loutas T, Kontsos A, Sotiriadis G, Pappas Y. On the identification of the failure mechanisms in oxide/oxide composites using acoustic emission. NDT \& E International. 2003;36:571-80.

[66] Standard Guide for Application of Acoustic Emission for Structural Health Monitoring.

[67] Grosse CU, Ohtsu M. Acoustic emission testing: Springer Science \& Business Media; 2008.

[68] Internationa A. ASTM E1316 - 96 Standard Terminology for Nondestructive Examination.

Philadelphia: PA, Ameri. Can Society for Testing and Materials; 1996.

[69] KATTIS S. Noesis-Advanced Data Analysis, Pattern Recognition \& Neural Networks Software for Acoustic Emission Applications.

[70] Hall MA. Correlation-based feature selection of discrete and numeric class machine learning. 2000 .

[71] McLachlan G, Peel D. Mixtures of factor analyzers. Finite Mixture Models. 2000:238-56.

[72] Merati A. A study of nucleation and fatigue behavior of an aerospace aluminum alloy 2024-

T3. International Journal of Fatigue. 2005;27:33-44.

[73] Anand L, Kothari M. A computational procedure for rate-independent crystal plasticity. Journal of the Mechanics and Physics of Solids. 1996;44:525-58.

[74] Zhang J, Huang Y, Mao C, Peng P. Structural, elastic and electronic properties of $\theta$ (Al 2 $\mathrm{Cu}$ ) and $\mathrm{S}(\mathrm{Al} 2 \mathrm{CuMg})$ strengthening precipitates in $\mathrm{Al}-\mathrm{Cu}-\mathrm{Mg}$ series alloys: first-principles calculations. Solid State Communications. 2012;152:2100-4. 